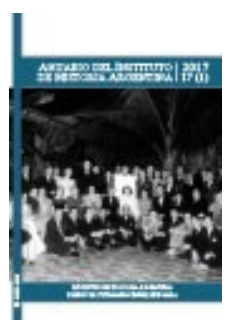

Anuario del Instituto de Historia Argentina, vol. 17, nº 1, e037, junio 2017.

ISSN 2314-257X

Universidad Nacional de La Plata.

Facultad de Humanidades y Ciencias de la Educación.

Centro de Historia Argentina y Americana

\title{
La OIT y las dictaduras latinoamericanas: una aproximación al Caso 842 contra Argentina
}

\author{
The ILO and the Latin American dictatorships: an introductory \\ approach to the study of the Case 842 against Argentina
}

\section{Luciana Zorzoli *}

* IdIHCS - Universidad Nacional de La Plata - CONICET, Argentina | Izorzoli@fahce.unlp.edu.ar

\section{PALABRAS CLAVE RESUMEN}

Argentina (1976-1983)

Este artículo realizará una aproximación al estudio del Caso 842 abierto en marzo de 1976 en las oficinas de la Organización Internacional del Trabajo (OIT), en Suiza, contra el gobierno militar argentino por violaciones a la libertad sindical. Los materiales que lo componen, por su riqueza y extrañez, lo convierten en una fuente inestimable para comprender tanto la acción internacional del autodenominado Proceso de Reorganización Nacional (PRN) como las relaciones del mismo con la

del Trabajo (OIT)

Caso 842 dirigencia sindical argentina, con las oposiciones internas y externas y con el organismo en cuestión. Centrándonos en las denuncias recibidas en el organismo, las respuestas argentinas y la estrategia desplegada por el PRN y sus aliados civiles y las acciones emprendidas por la OIT se revisará la dinámica del Caso y se dejarán planteados elementos para futuras indagaciones.

\section{KEYWORDS}

Argentina (1976-1983)

International Labour

Organization (ILO)

Case 842

Gabriel Osvaldo Martínez

Antonio Vitaic Jakasa

\begin{abstract}
This article explores the Case 842 opened in March 1976 at the offices of the International Labour Organization (ILO), in Switzerland, against the Argentinean military government for freedom of association violations. The materials collected in the Case, because of its exceptional richness, make it an invaluable source for understanding both the international actions of the so-called PRN and its relations with the Argentinean trade unions' leadership, the internal and external oppositions and the ILO. Focusing first on the complaints received by the Organization, secondly, on the Argentinean responses plus the strategy deployed by the PRN and its civil allies and finally on the actions undertaken by the ILO, we will review the dynamics of the Case and demonstrate that important questions remain open.
\end{abstract}


Este artículo realiza una aproximación al primer Caso abierto en la Organización Internacional del Trabajo (OIT) contra el gobierno militar argentino (1976-1983) por violaciones a la libertad sindical. El tratamiento que este Caso recibió y la documentación en él reunida a lo largo de todo el período dictatorial lo convierten en una fuente de inestimable valor histórico para comprender tanto la acción internacional del autodenominado Proceso de Reorganización Nacional (PRN) como las relaciones del mismo con distintos sectores, sean nacionales o extranjeros.

En esta exploración se dará cuenta de la rica variedad de elementos que el caso y de cómo, a través de su lectura y seguimiento, pueden documentarse diferentes aspectos de interés tanto para la historia política del período como para comprender las acciones de la OIT y las tensiones internas que recorrieron al organismo cuando debía aplicar los principios universales y estandarizados que supuestamente lo rigen desde su fundación.

El artículo se organiza en dos secciones: una primera que contiene los antecedentes necesarios para situar este estudio, y una segunda sección dedicada a presentar en forma sintética la exploración del Caso atendiendo a su desarrollo cronológico y principales actores. Como parte de la primera sección se describirá el funcionamiento de la OIT y del Comité de Libertad Sindical (CLS) para que pueda entenderse qué son los Casos abiertos en el organismo, cómo es su tratamiento y cuál es el objetivo de los mismos. Además, se revisará en perspectiva histórica la relación de Argentina con la OIT para contextualizar su importancia y captar así algunos de los cambios sucedidos durante el período. En la segunda parte, como se dijo, se presentarán los rasgos principales que tuvo el Caso 842 y se dejarán planteadas conclusiones preliminares surgidas de esta indagación.

\section{Antecedentes: el funcionamiento de la OIT y sus relaciones con Argentina}

Fundada en 1919 como parte de los tratados de paz después de la catástrofe de la Gran Guerra, la Organización Internacional del Trabajo (OIT) se pensó como un instrumento para fundar una paz mundial duradera basada en los principios de justicia social. $\underline{1}$

Su misión explícita era, como lo señalan Gerry Rodgers, Eddy Lee, Lee Swepston y Jasmien Van Daele (2009) la de promover, como alternativa a los movimientos revolucionarios de la época, el progreso social a través del diálogo y la cooperación. De allí que su Constitución establezca una peculiar organización tripartita $\underline{2}$ para construir un sistema internacional de normas del trabajo y la búsqueda de participación de los países no europeos. $\underline{3}$

En las últimas décadas se ha comenzado a explorar la importancia que tuvieron esas participaciones en la OIT para distintos gobiernos y agencias del Estado -especialmente para aquellas vinculadas a la regulación del mundo del trabajo, como el Departamento Nacional del Trabajo creado en 1907-. Uno de los elementos destacados es que tal participación permitió la formación de redes, promovió el debate nacional sobre la construcción de una legislación laboral comprehensiva y coherente, alentando la recepción de ideas y Convenciones generadas en el ámbito de la OIT, y hasta funcionó como espacio de legitimación para algunas estrategias de abordaje de la cuestión laboral en el país (entre otros Panettieri, 2000; Suriano, 2012; Suriano y Lobato, 2014; Caruso, 2014 y Stagnaro en prensa).

Aunque fructíferas, estas primeras participaciones, no estuvieron exentas de polémica, al menos en lo que respecta al sector sindical, pues en el ideario del movimiento obrero argentino primaban las ideas de inspiración revolucionaria que habían tenido por protagonistas a socialistas, anarquistas y comunistas hasta finales de la década del treinta, y no aquellas de paz social que promovía el organismo ginebrino. Entre los rechazos a la integración a la OIT se encontró el producido por la Unión Sindical Argentina (USA) y el de la 
Federación Obrera República Argentina (FORA) que impidieron la participación sindical en 1921, 1922 y 1923. A pesar de ellos, sin embargo, el envío de delegados fue regular especialmente con representantes de sindicatos grandes como La Fraternidad, la Federación Marítima y la Unión Ferroviaria, que ocuparon incluso importantes espacios dentro de la administración del organismo en la década del treinta (Belloni Ravest, 1969). Debe considerarse que no fueron las sindicales las únicas impugnaciones presentes durante este período pues, aunque menos conocidas, las resistencias del sector empresario argentino frente a la legislación laboral que se promovía desde esas redes internacionales también existieron, como bien destaca Caterina (2000) .

El surgimiento del peronismo en la década del cuarenta no produjo el fin de esas resistencias, aunque el nuevo gobierno le asignó una especial importancia política a la esfera internacional. Desde allí intentó revertir los ataques que sufría por ser visto como un pseudo-fascismo y propagandizar la "tercera posición" que esgrimió en su enfrentamiento con los Estados Unidos (Godio, 1980 y Zanatta y Aguas, 2005) . La defensa del peronismo le valió a la delegación tripartita argentina no pocas impugnaciones ante la propia OIT, como las sufridas en 1945, 1947 y 1950 ocasionadas por sectores agrupados en el Comité Obrero de Acción Sindical Independiente (COASI), producto de las disputas del propio Perón con sectores del "viejo” sindicalismo. De hecho, fue en ese contexto que se produjo la primera queja contra Argentina ante el Comité de Libertad Sindical denunciando la detención de obreros metalúrgicos en lo que se caratuló como el Caso $117 / 1954.4$

Su tratamiento correspondió a ese Comité por ser el órgano del Consejo de Administración de la OIT que desde 1951 analizaba las quejas presentadas ante el organismo por violaciones a los Convenios y Normas, especialmente aquellas violaciones que afectaban la libertad sindical (Gravel et al., 2001 y OIT/ Comité de Libertad Sindical, 2006) . La actividad del CLS se centraba en analizar las quejas presentadas -haciendo uso de mecanismos de informe que son confidenciales y reuniendo información según lo considerara necesariopara luego realizar recomendaciones públicas al Consejo de Administración sobre cada caso. Las recomendaciones que realizaba iban desde la sugerencia de concluir el examen de determinado caso, instar a que se llame la atención a un gobierno sobre las anomalías comprobadas a partir de las quejas -pues en el sistema de la OIT no había ni hay "castigos” por las transgresiones que puedan cometerse, y se consideran las menciones públicas como un fuerte llamado de atención- hasta sugerir vías de resolución y ayuda como la asistencia técnica. En tanto los informes y recomendaciones del CLS se hacían públicos constituyeron tempranamente un elemento de preocupación para los gobiernos afectados en su prestigio, y una forma de defensa y amparo para los denunciantes.

Como se dijo, la participación en la OIT en los años cuarenta y cincuenta fue parte de la actividad de propaganda justicialista y de la búsqueda de crear una organización regional que proyectara al peronismo en América Latina. Allí surgió el Comité de Unidad Sindical Latinoamericano (CUSLA) que se convirtió luego en la más conocida Asociación de Trabajadores Latinoamericanos Sindicalistas (ATLAS), opuesta a la Organización Regional Interamericana de Trabajadores (ORIT) cuyo enfrentamiento con el peronismo y con la Confederación General del Trabajo (CGT) fue público desde su fundación (Alexander, 2003 y Basualdo, 2014).

El ATLAS como empresa internacional de agrupamiento sindical no tuvo éxito a largo plazo y el mapa sindical internacional quedó finalmente dominado por la competencia entre la Federación Sindical Mundial (FSM), en cuya fundación participó la Confederación de Trabajadores de América Latina (CTAL) $)^{\frac{5}{5}}$ y por una ruptura de la misma, la Confederación Internacional de Organizaciones Sindicales Libres (CIOLS) y su filial, la ORIT. Desde entonces la política sindical internacional de Argentina y de América Latina orbitó alrededor de la confrontación de esos dos grandes agrupamientos que fueron además gravitantes en la OIT: la ORIT 
conducida por la política de la AFL-CIO norteamericana y la FSM con su Congreso Permanente de Unidad Sindical de los Trabajadores de América Latina (CPUSTAL), hegemonizada entonces por los partidos comunistas y a escala regional por los sindicatos de Chile, Uruguay y Cuba.

Si en un comienzo había primado una relación con la OIT de fuerte sesgo técnico y luego el peronismo había usado esa participación en clave propagandística, la ruptura del orden democrático del año 1955 generó un nuevo cambio en la forma de participación del país. Allí comenzaron las "designaciones de oficio" de los delegados obreros por imposición castrense, un mecanismo que se extendió hasta 1961 cuando en el marco de la normalización de la CGT se produjeron nuevamente designaciones representativas surgidas desde la central obrera, que permitieron exhibir posiciones críticas contra los gobiernos de Arturo Frondizi (19581962) y posteriormente de Arturo Umberto Illia (1963-1966).

Durante los años sesenta y hasta la llegada de la dictadura militar de 1976, la presencia argentina fue ininterrumpida en las Conferencias Anuales y se destacó la participación de los cuadros principales de la CGT y de importantes empresarios. Entre otros secretarios generales de la central obrera, participaron de las reuniones de la OIT Augusto Timoteo Vandor, José Alonso y José Ignacio Rucci, cuando éstos afianzaban sus relaciones con el sindicalismo "libre" de la AFL-CIO y la ORIT que terminó en la afiliación de la CGT a éste último agrupamiento en 1975, y que fuera confirmada en el Congreso Normalizador de 1986, ya concluida la última dictadura militar (Sangrilli, 2011) .

Este breve recorrido expone la estabilidad y sentidos que tuvo el vínculo entre la Argentina y la OIT, relación que, aunque no siempre ha sido destacado, fue clave en la organización de la legislación laboral argentina tanto como en la internacionalización de las organizaciones obreras identificadas con el peronismo. A esto debe sumársele que la OIT, quizás por su grado de apertura a organizaciones no gubernamentales y por su importancia entre los organismos internacionales, se convirtió tempranamente en un espacio de visibilidad y legitimidad que importó y mucho a gobiernos, ya fueran éstos civiles o militares.

\section{La apertura y trámite del Caso 842}

El golpe de Estado provocado por las tres Fuerzas Armadas (FFAA), en marzo de 1976 en Argentina, produjo reacciones tempranas en su contra, quizás porque la comunidad internacional y las redes de solidaridad estaban templadas ya a la luz de la experiencia chilena. El derrocamiento de Salvador Allende en 1973, y la instauración de un régimen basado en el terror y la persecución al mando del general Augusto Pinochet, convirtieron a Chile y a sus exiliados en un intenso núcleo de actividad y difusión de la situación represiva que enfrentaban varios países de América Latina (Bastias Saavedra, 2013; García, 2013; Angell, 2013; Verhaert, 2016 y Livingstone, 2017) .

El autodenominado Proceso de Reorganización Nacional (PRN) trató en ese contexto de distanciarse del ejemplo chileno presentándose como una dictadura "moderna”, no personalista, y cuya función era la de defender al país de ataques externos que impedían su desarrollo e incluso su estabilidad democrática y republicana. Buscó así apoyos internacionales que permitieran atraer capitales y créditos para apuntalar la transformación en marcha y contrarrestar los efectos de las críticas que comenzaban a surgir en su contra. Las relaciones bilaterales y la participación en organismos internacionales cobraron en ese contexto especial importancia, centralmente lo que sucedía en las Naciones Unidas y su Comisión de Derechos Humanos (Guest, 1990 y Lloret, 2016) y con la OIT y su Comité de Libertad Sindical. $\underline{6}$

A continuación presentaremos cómo fue el desarrollo del Caso 842 considerando las principales denuncias, las estrategias de respuesta del gobierno argentino y las medidas más destacadas que tomó la OIT durante su tratamiento. Cada uno de estos componentes, presentados en forma sintética, permiten captar la riqueza y 
complejidad del trámite y abren el camino para futuras exploraciones.

\section{Las denuncias por la situación represiva}

Las FFAA que derrocaron al tercer gobierno peronista justificaron el golpe de Estado alegando que el país se encontraba en una situación excepcional con riesgos de desintegración, que requería de su presencia para refundar la nación y colocarla en la senda republicana y democrática, un argumento que enfatizaron en el escenario internacional.

Los desafíos para esta política de inocentización comenzaron, sin embargo, en forma inmediata. Un día después de que las FFAA tomaran el control operativo del país, el 25 de marzo de 1976, la FSM envió a la OIT por telegrama la primera queja formal por la situación represiva que se desplegaba contra las organizaciones obreras y los trabajadores en Argentina. ${ }^{\underline{7}}$ En los siguientes siete días el crecimiento de las denuncias fue exponencial, sumándose entre otras la CIOLS; la ORIT; la Unión Internacional Sindical de Trabajadores Metalúrgicos; la Federación Internacional Sindical de la Enseñanza (FISE) y la Confederación Mundial del Trabajo (CMT). Con distinto grado de detalle, en todas las denuncias se declaraba que los militares habían intervenido la CGT, suspendido las actividades sindicales y bloqueado el activo de los sindicatos disponiendo de la libertad de reconocidos sindicalistas y violando los Convenios $87^{\underline{8}}$ y $98^{\underline{9}}$ del organismo, de los cuales el país era signatario.

Las denuncias fueron aceptadas por la OIT que dispuso su seguimiento como un Caso a ser tratado por el Comité de Libertad Sindical, cuyos informes serían remitidos periódicamente al Consejo de Administración y a la Conferencia Anual del organismo. La variedad de éstas denuncias requeriría un tratamiento especial que no es posible desarrollar en esta primera aproximación, pero si es dable señalar sus principales características para guiar sobre la composición documental del Caso.

Como se señaló, fue la acción de agrupamientos sindicales internacionales y sindicatos extranjeros la que indicó a la OIT sobre la necesidad de intimar al gobierno argentino para que respetara la legislación internacional relacionada con la libertad sindical. Todas las restricciones dispuestas eran enumeradas como prueba (suspensión del derecho de huelga, intervención de sindicatos, etc.) junto con los nombres de sindicalistas y trabajadores que se encontraban detenidos y, con el correr de las semanas, desaparecidos, después de su detención arbitraria por fuerzas de seguridad que abrumadoramente no se identificaban ni dejaban información sobre los procedimientos que llevarían a cabo o el destino de las personas detenidas.

El aporte de listados de trabajadores, delegados y dirigentes sindicales que se encontraban en esa situación impulsó al CLS a llevar un registro detallado y pedir al gobierno en forma periódica informes sobre las situaciones particulares de las personas mencionadas. A esto se sumaba que el Comité empezó a ser destinatario de cartas personales, ya sea requiriendo ayuda del organismo para averiguar el lugar de detención de familiares o compañeros de trabajo, denunciar los procedimientos represivos, o que buscaban dar testimonio de lo vivido con el fin de ampliar el conocimiento de la situación argentina en el exterior. La admisibilidad de esas misivas en el tratamiento del Caso fue materia de debate, y con el correr del tiempo se estandarizó como respuesta del Servicio de Libertad Sindical del Departamento de Normas Internacionales del Trabajo a las y los solicitantes una que indicaba que, con motivo del examen de quejas presentadas por organizaciones sindicales sobre violaciones de la libertad sindical, el CLS había pedido informaciones al Gobierno sobre ciertas personas, indicando si entre ellas figuraba o no el nombre de la persona por el que la carta reclamaba. Si el Comité no tenía en su listado a la persona en cuestión, se indicaba que para que pudiese ocuparse de ese caso sería necesario "que una organización sindical presentase una queja al respecto”, de modo que eran sólo admisibles las cartas institucionales, y no aquellas dirigidas por personas o grupos de personas a título individual. 
Para entender las implicancias de esta limitación, debe señalarse que sólo en dos oportunidades sindicatos argentinos se dirigieron al Comité para reclamar por la situación represiva. Una, en 1977, cuando la Central de Trabajadores de la Educación de la República Argentina (CTERA) denunció la detención de su Secretario General, Alfredo Bravo, que se encontraba preso a disposición del Poder Ejecutivo en la Jefatura de Policía de la ciudad de La Plata después de haber estado desaparecido por casi dos semanas (ver A-OIT, C842, 1/1977 Carta por la situación del Secretario General Alfredo Pedro Bravo del 20 de octubre de 1977). Y otra, denunciando la desaparición de una trabajadora y su esposo, escrita por "sus compañeros de trabajo" y enviada con la adhesión de la comisión directiva del Sindicato de Empleados de Entidades Financieras no Bancarias (ver A-OIT, C842, 1/1978 Carta del Sindicato de Empleados de Entidades financieras no Bancarias del 10 de enero de 1978).

Únicas en el expediente, estas dos cartas que no mencionaban otros casos de prisiones, desapariciones, ni situaciones represivas similares en el país, tampoco daban cuenta de la situación general del sindicalismo y de los trabajadores desde el golpe militar. La falta de denuncia de sindicatos argentinos ante el organismo fue sin duda una característica constitutiva del Caso 842, que solo se explica atendiendo a la estrategia trazada por el gobierno y que tácitamente acordaron los sindicatos.

\section{Las respuestas argentinas}

Como se verá a continuación, lo que consideramos aquí las “respuestas argentinas” son, en efecto, las dadas tanto por el gobierno militar como por los delegados sindicales -la actuación de los delegados empresarios fue generalmente de acompañamiento silencioso- ante el organismo. El recorrido cronológico demuestra que la estrategia de defensa de lo actuado por los militares en materia represiva fue una "operación" (como la llamó en algún momento el propio gobierno) coordinada, en la que participó el sector sindical como actor clave en casi todas las oportunidades.

De acuerdo con los mecanismos dispuestos por la OIT, cada una de las misivas recibidas como denuncias y admitidas en el Caso era informada al gobierno argentino vía el Ministro de Relaciones Exteriores y Culto para su tratamiento y respuesta. Este, como veremos, no optó por el silencio ni por la negación de los hechos, sino que decidió confrontar las denuncias y mostrar una peculiar disposición al diálogo, incluso actuando en Casos y quejas pendientes del período inmediato anterior. $\underline{10}$ Lo hizo a través de más de cuarenta respuestas firmadas por quien era entonces el Embajador Extraordinario y Plenipotenciario en la Misión Permanente de la República Argentina ante los Organismos Internacionales en Ginebra, el economista Gabriel Osvaldo Martínez. Martínez había sido nombrado en ese cargo por Perón en 1974, luego de una exitosa carrera diplomática. Antes se había desempeñado como asesor económico de la Embajada en Chile, había tenido posiciones en Bonn y Bruselas y había sido Jefe del Departamento de Comercio y Secretario de Comercio Internacional, donde se señala que tuvo una relación de amistad con el entonces ministro José López Rega (Guest, 1990, pp. 103-10) . Paradójicamente, su participación en el tercer gobierno peronista no lo invalidó para continuar con sus tareas en Ginebra con el cambio de régimen, por el contrario, y como testimonia el Caso 842, la Junta Militar encontró en él a uno de sus más destacados estrategas.

En su primera respuesta a las denuncias que contenía el Caso 842, Martínez informaba al organismo que las FFAA habían asumido la conducción del Estado "para garantizar el cumplimiento de la justicia y el pleno respeto de los derechos humanos”, usando un argumento que invertía la denuncia realizada por las organizaciones sindicales señalando que la "subversión”, y no el gobierno militar, era la responsable de la violación de los derechos humanos. Su mensaje daba cuenta también de las restricciones a la actividad sindical, justificadas según él porque se había "dispuesto que en adelante las organizaciones sindicales ajusten el ejercicio de sus funciones a la defensa de las legítimas aspiraciones de sus integrantes, evitando incursionar en áreas ajenas a su competencia", permitiéndoseles mantener activa su administración interna y 
la de las obras sociales sindicales pero no actividades de carácter político (ver A-OIT, C842, 1/1976 Carta de la Misión Permanente de la República Argentina ante los Organismos Internacionales en Ginebra, 20 de mayo, 1976). El modelo utilizado en esta oportunidad se repetiría en los años siguientes: extensos argumentos políticos sobre la situación que vivía el país antes de la irrupción militar y justificaciones instruidas del proceder de las FFAA en la esfera económica, social y política. Por la situación represiva, se insistía, debía culparse a los ataques externos o a las "fuerzas subversivas", negando todo plan sistemático por parte del Estado o de sus fuerzas de seguridad.

Esas respuestas constituían una parte de la estrategia diseñada por el gobierno militar. Su complemento, como se dijo, era la participación en las Conferencias Anuales con una delegación tripartita completa (con representantes sindicales $\frac{11}{}$, empresarios y del gobierno) y unida para mostrar "normalidad” y que, paradójicamente, ignoraba el trámite del Caso y las denuncias. Así sucedió en 1976, cuando ningún miembro de la delegación nacional habló ante la Conferencia Anual, remitió información alguna al CLS o realizó comunicaciones específicas al Director General o a los denunciantes (sobre la participación en ese año y la estrategia de instalación internacional del PRN ver Zorzoli, 2016b) .

Pese a esto y como se mencionó, las quejas siguieron en aumento y el grado de detalle de las mismas también se acrecentó, incorporándose datos sobre el modus operandi de las bandas militares y nombres de personas detenidas y desaparecidas. Esto llevó al gobierno argentino a profundizar su estrategia de defensa, contestando "en forma confidencial" a la CIOLS y la FSM sobre las denuncias presentadas -y remitiendo al CLS copia de esas notas- con el fin de mostrar su buena predisposición y tratar de revertir el efecto que las mismas pudieran tener. Las respuestas incluían un elemento inédito en las prácticas del gobierno militar hasta entonces: presentaban un listado de detenidos/as detallando quiénes estaban presos por el Acta Institucional nro. 2 de la Junta Militar (entre ellos el metalúrgico Lorenzo Miguel); quiénes por estar siendo investigados por presunta relación con organizaciones subversivas; quiénes por investigaciones de maniobras dolosas con fondos sindicales o en la función pública, y quiénes por haber sido condenados por Consejos de Guerra Especiales o por la Justicia Nacional en lo Criminal. Incluían asimismo un listado de "liberados", "expulsados” y "otras situaciones” donde se daba cuenta de la situación, por ejemplo, del dirigente sindical Oscar Smith, presumiendo que había sido "secuestrado por una organización subversiva” y asegurando que su ausencia no podía deberse a la acción de las FFAA pues éstas "no se habían visto nunca involucradas en hechos de esa naturaleza”. Se adjuntaba, para concluir, un largo listado de personas "sobre las que no se tiene información y que no se encuentran en ninguna cárcel del país” (ver A-OIT, C842, 1/1977, Confidencial Memorandum, enviado por la Oficina de la OIT en Buenos Aires, 30 de marzo 1977 y 4 de abril de 1977).

Junto a estas notas el gobierno argentino remitía una posterior al CLS en la que solicitaba que "se llame la atención a las organizaciones querellantes para que en sus reclamos no incluyan nombres de personas si no poseen todos los elementos de juicio suficientes para que las mismas sean consideradas presuntamente desaparecidas", pidiendo que se garantizara en cada caso contar con datos personales completos, algo que sabía el gobierno era de difícil realización, pero con lo que presionaría al CLS durante los años siguientes (ver A-OIT, C842, 1/1977 Carta de la Misión Permanente de la República Argentina ante los Organismos Internacionales en Ginebra, 9 de mayo, 1977). De ese modo el embajador Martínez mostraba que la estrategia de defensa incluía también velados ataques contra los denunciantes, que eran fustigados como irresponsables o "parte de una campaña contra el país”, tal como se hacía en Argentina y como harían también los delegados sindicales.

La estrategia gubernamental se encontró con inconvenientes al año siguiente, en 1977, en primer lugar por la decisión de los sectores sindicales de no acudir a la OIT como forma de presión para que se regularizara la situación de los sindicatos intervenidos y, especialmente, para que se aprobara la nueva ley de asociaciones 
profesionales que estaba en negociación desde marzo de 1976. $\underline{12}$

De todos modos el crecimiento de las quejas y la ausencia sindical argentina en Ginebra no eran los únicos problemas que enfrentaba el gobierno en Ginebra. En medio de la discusión con los sindicatos se produjo el secuestro y la desaparición de un asesor de la Unión Industrial Argentina (UIA) vinculado personal y administrativamente con la OIT. $\underline{13}$ Se trataba del sociólogo Antonio Vitaic Jakasa, que por su trabajo con el sector empresario había concurrido a la OIT en representación de los empleadores y había ocupado la presidencia de comisiones en varias oportunidades desde 1962, y desde 1972 ejercía además funciones como miembro pleno del Comité de Libertad Sindical. $\stackrel{14}{ }$ Su desaparición tuvo un impacto significativo en Ginebra -y provocó un seguimiento especial dentro del trámite del Caso- sumado a que ya integraban las Memorias del Director las reclamaciones contra el país y las recomendaciones del Comité de Libertad Sindical de requerir mayores informaciones y evaluar el progreso de la situación argentina en un nuevo informe (Boletín Oficial, Vol. LX, Serie B OIT 1977).

En este contexto, como se mencionó, el CLS recibió una primera denuncia de un sindicato argentino, CTERA, mostrando que la complejidad de lo que ocurría iba en aumento y que el acuerdo implícito entre la dictadura y los sindicatos argentinos de mantenerse prescindentes en el trámite del Caso estaba puesto en duda. Quizás por eso en la participación de 1978 se introdujeron tres novedades. En primer lugar, que el delegado sindical argentino -Alberto Serrano, del Sindicato Único de Trabajadores del Neumático Argentino- hablara ante el plenario de la Conferencia para revertir las denuncias acumuladas. Al mismo tiempo, a las detalladas cartas de respuesta que el embajador Martínez remitía al CLS se sumaron "informes" sobre la situación de libertad que se vivía en Argentina, con recortes de diarios y publicaciones varias.

Debe destacarse que en la trama interna del trámite la falta de crítica al gobierno y la falta de denuncia de situaciones represivas por parte de los delegados obreros argentinos y de los agrupamientos sindicales nacionales funcionaban como un amparo que impedía que el país recibiera llamados de atención más enfáticos. Esa actitud sindical, y también la empresaria, le permitían al gobierno aislar, aunque fuera parcialmente, las denuncias y cuestionar la legitimidad de los denunciantes, dispuestos como estaban a convencer que el tema debía ser dejado atrás o considerado un asunto interno que la comunidad internacional no podía entender y por lo tanto tampoco debía juzgar.

La segunda novedad que se produjo aquel año es que durante la Conferencia y en forma confidencial el ministro de trabajo se reunió "en contacto directo oficial" con un miembro de la OIT que participaba del trámite del Caso para realizar algunas “aclaraciones” sobre la situación del país. Según consta en la minuta sobre el encuentro incorporada al Caso:

(...) El ministro consideró que la expectativa puesta por el CLS [Comité de Libertad Sindical] en la nueva legislación es errónea. Hay una ley que está en preparación la cual continuará protegiendo a las organizaciones sindicales, pero será más liberal. Sin embargo la ley de asociaciones profesionales se sigue aplicando, estando solamente suspendidas ciertas actividades sindicales. El gobierno tomará medidas progresivas de normalización sindical. Aun cuando el ministro quisiera que la nueva ley se adopte rápidamente, quizá llegue a demorarse o a no ser adoptada nunca. (...) Por ahora siguen las estructuras sindicales, se prorrogan los mandatos de los dirigentes y delegados sindicales, se realizan asambleas y se mantienen las contribuciones. (...) En lo que concierne a los detenidos hay que distinguir cuatro categorías: liberados, a disposición del PE [Poder Ejecutivo], en espera de ser procesados y desaparecidos. La cuestión de los desaparecidos es una de las más difíciles según reconoció el propio Presidente [Videla]. En ciertos casos es posible que se hayan cometido excesos. (ver A-OIT, C842, 1/1978 “CONFIDENCIAL, Reunión con el General HT Liendo, Ministro de Trabajo de Argentina, Ginebra, 12/06/1978”) 
Las declaraciones de Liendo, que constituían una descripción acabada de su conciencia sobre la interna militar, las relaciones con los sindicatos y la situación represiva, eran un nuevo intento por reducir las expectativas de la OIT y del CLS y contener por ende el nivel de los reclamos contra el país, pero esta vez reconociendo en parte la verdad de las denuncias. Su estrategia no era de tipo personal, sino a tono con la política "clausurista" de Videla que buscaba que la visita a Buenos Aires de la Comisión Interamericana de Derechos Humanos (CIDH) dependiente de la Organización de Estados Americanos (OEA) limpiara su imagen externa y le permitiera cerrar el tema de las violaciones a los derechos humanos en el país con la imprecisa culpabilización de los mandos inferiores por haber cometido algunos “excesos” (Canelo, 2008, p. 139 y Novaro y Palermo, 2003) $\underline{15}$

Por eso a esta reunión confidencial se sumaría en agosto la recepción en Argentina del director de la OIT, Francis Blachard, y el permiso para que visitara el país un delegado del Director con la intención de evaluar la situación (ver Clarín y La Nación de agosto de 1978 y Basualdo, 2010, p. 413) . Se esperaba de esas visitas un informe que ayudara al CLS a comprender con precisión qué pasaba con los temas más sensibles: las intervenciones sindicales, las denuncias por detención y desaparición de trabajadores y sindicalistas y las cuestiones generales que hacían a la libertad sindical en el país, como la sanción de una nueva ley sindical que prometía el gobierno y esperaban los sindicatos.

Unos meses más tarde, en noviembre de 1978, se produjo el tercer cambio en la estrategia gubernamentalnacional, esta vez de la mano de los representantes sindicales. El dirigente Ramón Baldassini, de la Federación de Obreros y Empleados de Correos y Telecomunicaciones, participó de una reunión del Consejo de Administración y cuando se trató el informe producido sobre el Caso 842 intervino señalando que era "posible visualizar una evolución progresiva en lo que hace a la actividad sindical" en el país. Aclarando que él no quería "analizar ni debatir [en esa reunión] los fundamentos de razonabilidad que pudo haber tenido el gobierno argentino para dictar" las normas que restringían la actividad sindical, esperaba que las mismas se revirtieran a la brevedad, ante lo que, informaba a los presentes, se mostraba "optimista" (Actas de la 208va. reunión del Consejo de Administración, noviembre 1978). La política "clausurista” había funcionado ese año como debe hacerlo una orquesta, con la participación activa y armónica de todos sus miembros.

El año siguiente, en 1979, los militares buscaron continuar con la concordia pese a que el viaje se daba semanas después de la detención de quienes habían organizado la primer jornada nacional de protesta contra la política económica del gobierno, algo que había revitalizado las denuncias contra el país. $\underline{16}$ La trascendencia internacional de esas detenciones a sindicalistas había permitido que las denuncias se hicieran más allá del trámite del Caso y ocuparan parte del debate público de la Conferencia, dando visibilidad a grupos de exiliados como el Colectivo de Sindicalistas Argentinos en el Exilio liderado por Raimundo Ongaro (Dawyd, 2014) y hallando nuevas y más extendidas muestras de solidaridad (Actas de la sexagésima quinta Conferencia Anual de la OIT, 1979)..

Entre los representantes sindicales argentinos la represión del gobierno por la jornada de protesta de abril, y el anuncio de que finalmente habría una nueva ley sindical, no había provocado una reacción unánime. De hecho la respuesta de la delegación sindical en la Conferencia no fue de empatía con las intervenciones y delegaciones que cuestionaban la situación Argentina sino todo lo contrario, lo que demuestra que el enfrentamiento contra los planes económicos se consolidaba como tema de oposición pero otros temas como los que trataba el Caso- seguían siendo expresamente excluidos de la confrontación con el gobierno, primando el acuerdo que se hizo evidente ya en 1976.

La delegación sindical fue activa ese año explicando que la situación de restricciones que pudieran vivirse en el país se daba como producto de un ataque, no militar, sino de la izquierda "subversiva” y "terrorista”, algo que legitimaba al gobierno militar mientras denostaba las denuncias de los que no eran "verdaderos 
representantes del sindicalismo y la forma de vida argentina” (Actas de la sexagésima quinta Conferencia Anual de la OIT, 1979). Esa estrategia y especialmente la participación sindical en ella jugarían a favor del gobierno militar para evitar, otro año más, menciones o 'sanciones' que estigmatizaran al país, algo que despertó quejas en el mismo recinto. $\underline{18}$

La única interrupción en esa estrategia gubernamental-sindical-empresaria la produjo, poco tiempo después, la sanción del decreto-ley de asociaciones profesionales 22.105. Si hasta entonces todos los delegados habían actuado en forma unificada ya fuera ignorando las denuncias o bien cuestionando la legitimidad y veracidad de las mismas, la sanción de la ley en noviembre de 1979 produjo una pausa tanto en las relaciones entre los sindicatos y el gobierno militar como en lo que era hasta entonces la posición nacional frente al Caso. $\underline{19}$

Los dirigentes sindicales decidieron entonces enviar por primera vez una comunicación contra el gobierno militar que llegó a Ginebra el 30 de noviembre y salió de Buenos Aires el 22, seis días después de la promulgación de la ley. La nota denunciaba "la flagrante violación de los derechos sindicales en la República Argentina” y daba un instruido resumen de cómo eran afectados por el gobierno los derechos consagrados en varios tratados internacionales, amén de en los Convenios 87 y 98 de la OIT sobre Libertad Sindical. Esta nota iba firmada por la Mesa Nacional de la Conducción Unificada de los Trabajadores Argentinos (CUTA) que reunía a las dos corrientes sindicales del peronismo ortodoxo, la denominada Comisión de los 25 y la Comisión Nacional de Trabajo (CNT), y solicitaba a la OIT que se los considerara como “denunciantes” del gobierno argentino dándole intervención en las actuaciones al Comité de Libertad Sindical, el mismo que habían ignorado por completo hasta entonces. Pero en su misiva la CUTA no hacía mención, coherente con la postura adoptada desde 1976, a ningún elemento exógeno a la nueva ley, o anterior en el tiempo, que pudiera indicar que existían o habían existido en Argentina violaciones a los derechos humanos y sindicales. Pedían incorporarse al trámite ignorando de hecho la historia del Caso y su desarrollo, y sin romper el acuerdo fundante de su relación con el gobierno militar.

Cierto es que la nota manifestó una oposición unánime a la ley pero a partir de allí las estrategias sindicales se dividieron, algo que se ocupó de informar con sumo detalle el embajador Martínez en sus misivas al organismo, destacando que un porcentaje muy significativo de sindicatos se adecuaba a la ley dejando su breve actuación en el Caso 842 como marginal (Zorzoli, 2016a) . A esto se sumó que la sucesión presidencial, que se había resuelto a favor del general Roberto Eduardo Viola en octubre de 1980, le daba mayor margen de negociación al "nuevo” gobierno. $\underline{20}$ Pese a eso, y por motivos que no pueden abordarse en este breve artículo, la interna militar nunca cesó y finalmente impuso la salida de Viola, permitiendo el regreso del tono "refundacional" de manos de los sectores que se han denominado "duros" de las FFAA, produciendo un nuevo cambio en la situación interna del país con consecuencias relevantes (Yannuzzi, 1996 y Canelo, 2008).

Claro que antes el gobierno de Viola había realizado tratativas para asistir a la Conferencia Anual de 1981 en "unidad" con los sectores obreros y empresarios, y aunque las respuestas evidenciaron que se estaban produciendo cambios en el clima político nacional (pues no asistieron los sindicalistas congregados en la “CGT Brasil” que constituían la minoría), logró participar con diecinueve secretarios generales, agrupados en lo que sería la Intersectorial CNT-20. $\underline{21}$

Para el gobierno argentino esa participación fue más sencilla que la de años anteriores pues el tratamiento del Caso no fue central y en la Conferencia no hubo expresiones de rechazo contra el gobierno como hasta entonces, seguramente producto de las expectativas frente al cambio presidencial. El gobierno militar logró de ese modo por quinto año consecutivo que se esperaran "futuras comunicaciones" y mayor información, evitando así sanciones que perjudicaran más su posición internacional. 
Como se sabe, ante el agotamiento de la "lucha contra la subversión” y la crisis de una reforma económica con consecuencias devastadoras, se produjo al interior de la coalición golpista un desplazamiento de Viola con el fin de encauzar y continuar los planes refundacionales propuestos por el PRN en marzo de 1976. Los protagonistas de la nueva cruzada estaban bajo las órdenes del general Leopoldo Fortunato Galtieri, que articulaba tres elementos como los centrales de la nueva etapa: el retorno de la ortodoxia económica liberal, el acercamiento estratégico con los Estados Unidos y la conformación de un partido político (el Movimiento de Opinión Nacional) que le permitiera al gobierno heredarse a sí mismo (Canelo, 2008, p. 178) .

Entre la asunción de Galtieri y el cimbronazo que implicó la “recuperación” militar de las islas del Atlántico Sur el 2 de abril, hubo poco tiempo para cambios significativos, ya sea en el tratamiento internacional de la situación argentina como en su interior. Fue durante la guerra con Inglaterra que una delegación sindical se reunió con Galtieri y viajó a Ginebra encontrando un panorama nuevo para el país (Crónica, 28/05/1982). Quienes habían denunciado a Argentina en el exterior, mayoritariamente, expresaban ahora su solidaridad con la lucha por la soberanía territorial y la recuperación de las islas, produciendo de algún modo la evaporación de lo acumulado en el Caso. La derrota militar profundizó ese efecto dejando aislada la mirada internacional y las denuncias del Caso 842, que quedaron muy lejos del escenario local y de las preocupaciones de los actores políticos en Argentina, algo que colaboró quizás en invisibilizar hasta hace poco tiempo su trascendencia.

Se entiende aquí que la evaluación de la magnitud de las denuncias es tan destacable como lo es que la delegación Argentina se constituyera, de hecho, en un frente único entre empresarios, dirigentes sindicales y gobierno militar para ocultar o defender la acción represiva. Su trascendencia supera temáticamente a la relación de la OIT con Argentina cuando en el país se produjeron violaciones sistemáticas a los derechos humanos y sindicales, e ilumina cómo, variando sus estrategias en el tiempo -desde el silencio político y la acción diplomática hasta la defensa de las "respuestas argentinas" a supuestos "problemas internos"- los distintos sectores que integraron la delegación nacional intentaron minimizar el efecto que pudiera tener el Caso, algo que no dejó de preocuparles hasta el propio final del gobierno de facto.

\section{Las acciones de la OIT y del CLS}

Por último, requieren una mención especial las acciones emprendidas por la OIT y su Comité de Libertad Sindical durante los años 1976 y $1983 . \underline{22}$

Las mismas incluyeron, en lo esencial, tres aspectos. Por un lado, la publicación de informes sobre las novedades del Caso presentados al Consejo de Administración, que constituían el elemento más preocupante para el gobierno -junto con las denuncias de delegados durante las Conferencias Anuales- por su carácter público. En segundo lugar, el CLS mantuvo un seguimiento exhaustivo de tres situaciones puntuales que eran centrales en las denuncias: la intervención de sindicatos, el dictado de una nueva ley de asociaciones profesionales y la detención y desaparición de personas, registrando toda la información que recibieran e instando al gobierno a responder en particular por cada una de ellas. En tercer lugar, el organismo acordó con el gobierno que un representante del director de la OIT, Francis Blachard, visitara el país con intención de evaluar la situación Argentina en dos oportunidades, en 1978 y 1980 -esto, como se mencionó, se permitía en el marco de una política específica del gobierno del general Videla que pretendía "superar" las denuncias contra el país, admitiendo visitas internacionales como la de la CIDH y estas de la OIT-. El enviado fue un abogado y profesor de la Universidad de Roma que había participado en el trámite de otros casos, Antonio Malintoppi, y se esperaba que sus informes ayudaran a comprender con precisión qué pasaba con los temas más sensibles presentes en el trámite en Ginebra, las intervenciones a organizaciones sindicales, las denuncias por la detención y desaparición de sindicalistas y las cuestiones generales que hacían a la libertad 
sindical en el país.

Podía aventurarse que in situ la OIT podía corroborar lo que estaba siendo denunciado por las organizaciones sindicales internacionales y por los exiliados argentinos, pero eso dependía en gran medida de qué dijeran los informantes y la orientación general de la indagación que llevara adelante Malintoppi, algo que revisaremos en forma breve a continuación.

La primer visita a Buenos Aires se produjo entre el 27 de agosto y el 3 de septiembre de 1978. Durante esos días Malintoppi se entrevistó con el ministro de trabajo, visitó la sede central de la CGT intervenida, tres sindicatos -la Unión Obrera Metalúrgica, la Asociación Obrera Textil y la Unión de Obreros de la Construcción de la República Argentina- y dos fábricas, entrevistándose con interventores, dirigentes sindicales, empleadores y miembros del gabinete nacional de segunda línea. El resultado fue desalentador para quienes cifraban en la visita la posibilidad de un endurecimiento del organismo con el gobierno militar pues se repitió el esquema de acuerdos que se hacían evidentes en las Conferencias Anuales, donde el sector sindical y el sector empresario acompañaban los argumentos gubernamentales manteniéndose distantes de todas las denuncias por la represión que estaba llevándose adelante en Argentina. En el informe presentado por Malintoppi esas explicaciones progubernamentales sumaron, de hecho, nuevos argumentos. Tal es el caso de las intervenciones sindicales que el gobierno había adjudicado al desorden de una situación crítica y que, según varias de las entrevistas realizadas en la visita con autoridades y representantes de los empleadores, se debían también a que dirigentes sindicales se habrían "prevalido de sus funciones estatutarias con fines manifiestamente políticos y aun, a veces, de provecho personal”, algo que Malintoppi señalaba, no había sido negado por las fuentes sindicales. Lo que los dirigentes sindicales sí habían "refutado" de las explicaciones oficiales al respecto, era que los procedimientos judiciales "se hayan desarrollado con la celeridad que se imponía a fin de condenar a los culpables y de permitir que se absolviera a los inocentes”. Malintoppi decía en su informe que el movimiento sindical estaba disconforme por la incertidumbre que pesaba "sobre la suerte de cierto número de sus dirigentes presos", y que sintéticamente habían afirmado, para conocimiento de la OIT y por si quedaran dudas de que estos "presos" de los que hablaban no tenían nada que ver con los otros que estaban en discusión internacional, que los dirigentes sindicales por los que reclamaban (aquellos a disposición del Poder Ejecutivo) y los organismos sindicales argentinos “nada tenían que ver con grupos subversivos” (Boletín Oficial, Vol. LXII, 1979, Serie B, OIT).

Pese a eso, el informe se detenía en la cuestión de las desapariciones que había sido tan insistentemente denunciada por las organizaciones sindicales internacionales en el trámite del Caso. El informe repetía, a grandes rasgos, lo que era ya la explicación oficial sobre el tema, a saber: como algunas personas habían alterado su identidad producto de la clandestinidad, e incluso podían haber muerto en esa circunstancia, no podía identificárselas. Además, en el fragor del enfrentamiento, podían haberse producido “excesos”, pero siempre en cumplimiento de la tareas de combate, lo que hacía que la cuestión de las desapariciones no fuera ni un plan ni una responsabilidad directa del gobierno, el cual que no tenía tampoco una vía de resolución satisfactoria que ofrecer al respecto. En el reporte de Malintoppi no hay indicación alguna de que los dirigentes sindicales se refirieran al tema de los desaparecidos en sus entrevistas, ni a los secuestros, la militarización de los espacios de trabajo ni a otras violaciones a los derechos humanos y sindicales, manteniendo un silencio que era concordante con cómo habían actuado hasta entonces en las Conferencias de la OIT.

Sobre las intervenciones sindicales y los fondos de las obras sociales, en cambio, el informe sí contaba con la activa participación sindical que reclamaba el cese de las medidas y la normalización de los sindicatos, pero alentaba a la OIT a creer que el país iba por buen camino. En primer lugar Malintoppi señalaba que en ciertos sindicatos estaban intervenidas las directivas nacionales "pero no lo están las directivas locales”, y que en base a las opiniones "manifestadas por ciertos dirigentes trabajadores y empleadores parece que, 
efectivamente, la situación actual ha evolucionado en el sentido de una menor rigidez en la aplicación de las restricciones" sobre la actividad sindical, citando como ejemplo de esa situación las reuniones entre distintos grupos dirigentes en forma pública.

El informe marcaba su línea de interpretación de lo que estaba aconteciendo en el país alimentado por lo que los interlocutores elegidos habían decidido exponer ante la OIT. Cuando en él se analizaba "la situación y el funcionamiento" de los sindicatos, que era un tema de evidente centralidad, Malintoppi señalaba lo siguiente: "los poderes de los interventores parecen haber abarcado al comienzo todas las facultades conferidas por los estatutos" pero que en sus visitas había podido conversar con dirigentes sindicales “que vienen encargándose desde hace algún tiempo de ciertos aspectos de la dirección sindical, aunque las funciones del secretario general siguen siendo ejercidas principalmente por el interventor” y sumaba a esto que "(...) En lo que concierne más generalmente al ejercicio de los derechos sindicales, el representante del Director General señaló que ningún sindicato puede celebrar actualmente elecciones de dirigentes. Una gran mayoría de estos últimos continúan al frente de sus sindicatos o secciones sindicales y gozan de autoridad legal para la gestión interna de sus organizaciones, puesto que sus mandatos han sido prorrogados. (...). Las reuniones de comisiones directivas sindicales se realizan, salvo en los casos en que los poderes de tales órganos hayan sido confiados a autoridades interventoras. Para las asambleas no parece haber dificultad en conseguir el permiso necesario, aunque se le señalaron al representante del Director General algunas excepciones. Según su informe, tampoco la prensa sindical tropieza con dificultades. La recaudación de las cuotas sindicales se sigue efectuando generalmente mediante el descuento por el empleador” (Boletín Oficial, Vol. LXII, 1979, Serie B, OIT).

Cabe preguntarse si la realidad que captaba el informe de Malintoppi era o no fiel a lo que estaba sucediendo en la administración de los sindicatos y en las actividades que desarrollaba la dirigencia sindical, o era sólo una pantalla "favorable" al gobierno. Sabemos que el año 1978 transcurrió con una baja en los conflictos fabriles, que el gobierno gozó de un nuevo consenso producto de la "fiesta nacionalista” que trajo el campeonato mundial de fútbol, y que sus disputas internas habían sido circunstancialmente superadas con la designación de Videla para un segundo mandato que cerraba el período de excepción que le había permitido ser simultáneamente comandante en jefe del Ejército, integrante de la Junta Militar y Presidente de la Nación. No sin dificultades Videla había comenzado a implementar su política clausurista y apostado a una renovación del gabinete con el único sentido de afianzar la posición de Martínez de Hoz, en el que cifraba todas sus esperanzas de éxito. En ese marco la actividad sindical de los dirigentes no había encontrado mayores problemas y las prórrogas de mandatos sindicales habían seguido en franco aumento mientras que las intervenciones a organizaciones gremiales se habían reducido drásticamente (Zorzoli, 2016a, pp. 227-58 y en prensa) .

Analizando el cuadro general puede sostenerse que el informe de Malintoppi reflejaba adecuadamente una parte de la vida sindical argentina, esa que hacía a las dirigencias sindicales del peronismo ortodoxo, incluso en algunos casos a aquellas que se encontraban formalmente intervenidas. $\underline{23}$

El segundo informe realizado por Malintoppi se difundió poco antes de la Conferencia de 1981, como producto de su segunda misión de contactos directos llevada adelante entre el 7 y el 13 de diciembre de 1980 en Buenos Aires. En ese segundo informe se detallaba que Malintoppi había tenido una nueva ronda de entrevistas con funcionarios, dirigentes sindicales y empresariales en los locales de la OIT en Buenos Aires, había visitado importantes sindicatos intervenidos (la Asociación Obrera Textil, la Unión Obrera Metalúrgica, la Federación de Obreros y Empleados de Correos y Telecomunicaciones, la Federación Argentina de Trabajadores Rurales y Estibadores y la Unión Obrera de la Construcción de la República Argentina) y escuchado a familiares de sindicalistas “detenidos o desaparecidos”. $\underline{24}$ 
De todo esto había extraído una conclusión que transmitía a la oficina en Ginebra: el centro del conflicto para los sindicatos giraba en torno a dos temas: el deterioro de la situación económica general y la aplicación de la ley sindical y su "anexo", la ley de obras sociales. Del informe se desprende, según el CLS que lo transcribió para su tratamiento, "que el sentimiento dominante entre las organizaciones de trabajadores era que la ley era totalmente contraria a los intereses de los trabajadores (...) En opinión de los sindicatos, la ley [era] restrictiva en cuanto a las posibilidades de acción de las organizaciones en materia de actividades lucrativas y en materia de prestaciones sociales”. Sobre el contexto general y la situación política imperante en Argentina el informe señalaba que se vivía una cierta mejora en cuanto a las relaciones de trabajo "aunque las estructuras existentes en 1978 -prohibición de huelgas y de elecciones sindicales, así como de la negociación colectiva, intervención de ciertos gremios y prórrogas en los mandatos de los dirigentes de otros gremios- siguen prácticamente iguales, en el plano de los hechos, se ha avanzado algo en la vía de la normalización” (Informe en Boletín Oficial Vol. LXIV, 1981 Serie B, núm. 1, OIT).

Las voces sindicales eran discordantes sobre este punto. Si bien la mayoría de los dirigentes gremiales indicaron a Malintoppi que no podía hablarse de normalización "mientras no se restableciese la libertad sindical” pidiendo el cese de las intervenciones, los dirigentes de gremios intervenidos -dice el informe“coincidieron en afirmar que, aunque habían pasado por momentos difíciles, sus actividades se desarrollaban ahora con cierta normalidad”. Incluso en "dos de los cinco gremios intervenidos (...) la afiliación había aumentado desde que se produjo la intervención” (Informe en Boletín Oficial Vol. LXIV, 1981 Serie B, núm. 1, OIT).

En otros temas, en cambio, la dirigencia sindical había actuado ante la segunda misión de la OIT como lo había hecho en la primera, manteniendo silencio especialmente en la discusión sobre las detenciones y desapariciones de personas permitiendo al Comité indicar que "según el informe de misión, estas desapariciones o detenciones parecen haber tenido lugar, sobre todo, en los primeros meses después de los acontecimientos de 1976. En particular, el representante del Director General no tiene elementos que prueben que haya habido nuevas detenciones de esta índole desde que visitó el país en 1978 y concretamente durante 1980”, ante lo que aclara que los dirigentes sindicales habían planteado su preocupación por dos situaciones. De todo lo sucedido hasta entonces los sindicalistas consultados por Malintoppi habían expresado su preocupación por dos personas, ambos secretarios generales de sindicatos, que se encontraban privados de su libertad a disposición del Poder Ejecutivo Nacional. $\underline{25}$

Fruto de este informe el CLS observó que no se había producido ningún elemento nuevo sobre el tema de los desaparecidos "lamentando vivamente que, aun habiendo testimonios sobre numerosos casos de desapariciones, no hayan podido ser esclarecidas hasta ahora” (Boletín Oficial Vol. LXIV, 1981 Serie B, núm. 1, OIT). $\underline{26}$

De los informes se desprende que el enviado por la OIT privilegió como voces autorizadas a los dirigentes sindicales (frente a otras posibles, como los familiares de personas detenidas desaparecidas que estaban ya organizados en Argentina) y que restringió su actividad a la concreción de entrevistas sin adentrarse en espacios más complejos para el régimen, como podrían haber sido las principales fábricas y conglomerados obreros de Buenos Aires, Rosario, Córdoba, Tucumán o Mendoza. De este modo el CLS y el organismo de conjunto quedó privado de un retrato menos complaciente -que sin duda no habría podido repetirse en una segunda visita - y a lo sumo pudo confirmar que existía en el país un consenso para la acción represiva del que participaban dirigentes sindicales, empresarios y militares, algo que sin duda dificultaba la posición de la OIT y las medidas que desde allí pudieran tomarse. 


\section{Conclusiones}

Como se vio en este recorrido tanto las denuncias que recibió el país, como la participación en las Conferencias Anuales y las actuaciones dentro del trámite del Caso 842 del CLS, contienen información que enriquece y amplia nuestro conocimiento sobre una serie amplia de temas y actores vinculados a la historia reciente y a la relación entre el organismo ginebrino y el país.

Analizando el Caso puede verse cómo éste fue, simultáneamente, un punto de tensión para la política internacional del gobierno militar, que siguió su tratamiento con cuidado y buscó evitar que tuviera efectos que les fueran perjudiciales, y a la vez una oportunidad para que el mismo establezca diálogos, negociaciones y acuerdos en la esfera interna de la política argentina con efectos en el exterior.

La actitud frente al Caso de las dirigencias sindicales nacionales actuantes en la OIT muestra, por ejemplo, que las mismas actuaron contra las denuncias vinculadas a la violación de los derechos humanos y sindicales conformando un frente único con el gobierno militar y los empresarios para dificultar el avance de las investigaciones y los posibles castigos que pudiera tener el gobierno por su política represiva. Fueron, sin embargo, sumando progresivamente sus voces a las disidencias contra los planes económicos del PRN, tal como lo indicó, para el caso de las dirigencias políticas en general, María de los Ángeles Yannuzzi en su trabajo clásico sobre el tema (1996).

La acción desplegada por una amplia variedad de organizaciones sindicales, nacionales e internacionales, debe ser también destacada, visibilizando a un actor que actuó con rapidez y determinación y que suele ser subestimado frente, por ejemplo, a los organismos de derechos humanos del período. Hablamos de sindicatos, federaciones y confederaciones de diversos países, cuyas redes en Argentina son, hasta hoy, mayormente desconocidas. La indagación sobre sus vínculos con sectores del sindicalismo argentino y sobre cómo, por ejemplo, las mismas construyeron los listados que enviaban al CLS, y cómo enriquecieron y precisaron su conocimiento sobre lo que sucedía en el país, está aún pendiente.

Por último, un balance general de las acciones y posiciones adoptadas por la OIT y su CLS frente a las violaciones sistemáticas a los derechos humanos y sindicales en Argentina en el período persiste como tarea pendiente. Lo analizado hasta aquí permite, por un lado, reconocer la importancia que esas acciones tuvieron (cuya evidencia más clara fue la preocupación del gobierno militar sobre lo que pasaba en Ginebra y la febril actividad del embajador Martínez al respecto) y, por otro, avanzar en la reflexión sobre las implicancias que tuvo el grado de conocimiento que existía en el organismo sobre la realidad argentina. Se presenta como una limitante, por ejemplo, la elección de interlocutores "institucionalmente reconocidos" o la valoración de la actitud de la dirigencia sindical nacional como clave para endurecer o no la posición contra el gobierno militar. Pero esas opciones, si impidieron que el organismo actuara de manera más determinada entonces, no obstaculizaron un detallado tratamiento tanto en los Informes del Caso, en el seguimiento hecho sobre temas centrales (como las intervenciones, las desapariciones y las restricciones a la libertad sindical) y en los viajes realizados por Malintoppi. Tampoco vedaron la seria preocupación que puede verse en el seguimiento del trámite del Caso a lo largo de los años, aunque parece evidente que los recursos para producir sanciones efectivas fueron escasos.

Es la continuidad de esta línea de investigación la que puede ofrecernos la integración de las esferas internacional y nacional, que se mantuvieron artificialmente desconectadas en el estudio de casos nacionales. Esa misma continuidad permitirá aportar una valoración, aunque sea provisoria, sobre las acciones de la OIT en este período que colabore con ampliar nuestro conocimiento sobre la historia del organismo en América Latina. 


\section{Notas}

1 La OIT se estableció como agencia especializada e independiente de la Liga de las Naciones pero contó con antecedentes significativos en el siglo XIX, especialmente la Asociación Internacional para la Protección Legal de los Trabajadores (IALL - International Association for Labour Legislation) que rivalizó con los principios propuestos por la Primera y Segunda Internacional. Un estado de la cuestión sobre la historia de la OIT desde su fundación, considerando tanto las lecturas que brindó la propia institución como aquellas realizadas desde las Ciencias Sociales puede verse en ILO histories: essays on the International Labour Organization and its impact on the world during the twentieth century, especialmente en el aporte de Jasmien van Daele (2010) . Sobre la Liga de las Naciones y la OIT ver entre otros McPherson y Wehrli (2015) .

2 La Constitución de la OIT aprobada en 1919 y sus modificaciones posteriores establecieron como método de gobierno del organismo el tripartismo, (2:1:1) -otorgando el derecho de voto tanto para gobiernos como para los representantes obreros y empresarios de los países miembros- y como forma de promoción de sus principios la adopción de Convenios y Recomendaciones internacionales a ser sometidas a las autoridades nacionales para su ratificación. Junto con esto la OIT creó un sistema de inspección en la búsqueda de garantizar el cumplimiento de las normas adoptadas y recomendadas globalmente.

$\underline{3}$ Argentina fue uno de los países latinoamericanos en sumarse al organismo desde su fundación. También lo hicieron Bolivia, Brasil, Chile, Colombia, Cuba, El Salvador, Guatemala, Haití, Honduras, Nicaragua, Panamá, Paraguay, Perú, Uruguay y Venezuela.

4 Entre los casos más importantes presentados ante el CLS sobre Argentina puede mencionarse el Caso 172, que pedía la intervención del organismo por la represión de la huelga bancaria en 1957; el Caso 192 denunciando la represión sufrida por los trabajadores ferroviarios en 1958; el Caso 216 sobre la detención de Andrés Framini; el Caso 399 por el enjuiciamiento de dirigentes sindicales a raíz del Plan de Lucha aprobado en 1963 y el Caso 503 denunciando las intervenciones sindicales y varias suspensiones de personerías gremiales en 1967.

$\underline{5}$ En 1964 la CTAL se transformó en el Congreso Permanente de Unidad Sindical de los Trabajadores de América Latina (CPUSTAL), ver Alexander (2009) .

$\underline{6}$ Que la esfera internacional tuviera relevancia para el PRN no quiere decir que no hubiera en el seno de las FFAA una intensa puja sobre cuál era la mejor estrategia internacional a desarrollar, como bien lo mencionan Novaro y Palermo (2003) y Canelo (2008) .

$\underline{7}$ De aquí en más todas las menciones sobre el Caso 842 sin indicación en contrario se basan en el trabajo de archivo realizado en el Archivo de la OIT en Ginebra, Suiza. Para su mejor identificación se utiliza la siguiente signatura propuesta por esta investigación: Archivo Organización Internacional del Trabajo, Caso Nro., Nro. Carpeta / Año. Se propone como forma abreviada: A-OIT, CNro, Nro. Carpeta/ Año. En el caso de esta cita corresponde: A-OIT, C842, 1/1976.

$\underline{8}$ El Convenio 87 es el relativo a la libertad sindical y a la protección del derecho de sindicación. La Argentina lo ratificó en enero de 1960, diez años después de su entrada en vigor (ver ILO, Ratificación del C087).

9 El Convenio 98 es el relativo al derecho de sindicación y de negociación colectiva. La Argentina lo ratificó en septiembre 1956, cinco años después de su entrada en vigor (ver ILO, Ratificación del C098).

$\underline{10}$ Con la intención de “cerrar” casos pendientes contra Argentina el embajador Martínez emitió en 1976 respuestas por denuncias preexistentes, como las que se referían a las acciones violentas desarrolladas por grupos paramilitares, como la Triple A. Alegó en todos los casos que se trataba de "responsabilidades del gobierno anterior" y que "la ola de violencia" que se vivía en Argentina estaba provocada por la acción 
terrorista que el gobierno estaba dedicado a "contrarrestar". Ver por ejemplo la respuesta emitida el 22 de octubre de 1976 referida al Caso nro. 836 (OIT, Boletín Oficial, Vol. LX, 1977, Serie B).

11 Los representantes sindicales fueron designados durante el período por un plenario de secretarios generales convocado por el gobierno especialmente para ir a Ginebra, que contó siempre con una nutrida participación. El gobierno se ocupó en todos los casos de que la designación fuera firmada por los presentes y certificada por un escribano público, para evitar que se cuestionara la legitimidad de la comitiva.

$\underline{12}$ En 1977 la dirigencia sindical advirtió que la estrategia gubernamental requería de su participación y usó esa oportunidad para presionar por promesas incumplidas, pidiendo como compromiso previo al viaje que lo que se decía a puertas cerradas (esto es que habría nueva ley de asociaciones profesionales y una rápida normalización sindical con la paulatina liberación de los dirigentes detenidos "sin proceso") se hiciera público y constituyera una política oficial de toda la Junta Militar. Presionaban -con o sin conocimientosobre el talón de Aquiles del propio ministro, que contaba para sus promesas con el apoyo de los sectores "politicistas" del gobierno tanto como con la férrea oposición de los que se negaban cualquier insinuación de convergencia cívico-militar o de apertura política. Cuando todo parecía indicar que se había llegado a un entendimiento, el sector gremial decidió no concurrir a la OIT (ver La Nación 26/05/1977). El punto de ruptura era la negativa a indicar públicamente los plazos en los que se procedería a aprobar la nueva ley por un gobierno que había optado ya por la fórmula de "objetivos y no plazos”.

$\underline{13}$ Vitaik Jakasa fue secuestrado el 6 de mayo de 1977. Existe muy poca información sobre su secuestro y desaparición, denunciada ante la CONADEP e investigada bajo el legajo nro. 3024. Su secuestro tuvo un fuerte impacto internacional (ver entre otros New York Times, 15/05/1977) y recibió un cuidado especial del gobierno. El mismo incluyó el debate en la Comisión de Asesoramiento Legislativo (CAL) sobre la contribución de Vitaik Jakasa al país, lo que permitió que en un trámite impulsado por el ministro Liendo se le concediera una pensión graciable para su mujer e hija (ver trámite legislativo "por el cual se acuerda una pensión a la Sra. Jenka de Vitaic”, Expediente 125, 1978, Archivo General de la Nación/ Departamento Archivo Intermedio, Fondo CAL).

14 En 1976, fue designado como Vicepresidente de la Asamblea Anual por el sector empresario, algo que destacó la prensa como un respaldo institucional al país (ver por ejemplo Clarín, 03/06/1976). Post facto la interpretación opuesta es perfectamente posible: que su designación en tan destacada posición se haya realizado para protegerlo y darle visibilidad ante la situación de riesgo que había en Argentina. En su participación de 1976, Vitaic Jakasa no mencionó la situación represiva en forma explícita, aunque por sus tareas estuvo involucrado en discusiones sobre libertad sindical y no puede haber escapado a su conocimiento la apertura del Caso 842 ni las respuestas dadas por el gobierno a través del embajador Martínez.

15 La teoría de los “excesos” como explicación oficial sobre las desapariciones se hizo pública cuando Videla respondió al Episcopado Argentino sobre las posibles causas de las desapariciones de personas en 1977. En esa respuesta indicaba que las mismas se podían deber al pase a la clandestinidad de personas que dejaban de usar sus datos personales, a su asesinato en el marco de ajusticiamientos internos de los grupos subversivos, a exilios no registrados, a la incapacidad de reconocimiento de los muertos en situaciones de combate y por último, a “excesos” militares (Mignone, 1986, p. 66) .

16 Como había sucedido los años anteriores, las voces gubernamentales contrarias a participar seguían existiendo en el seno de las FFAA. Ver sino las declaraciones del ministro del interior, general Hanguindeguy, deseando que no se dejara participar a la Argentina en la OIT y así "desligarse de esa organización” (Clarín 30/05/1979). 
17 El Colectivo de Sindicalistas Argentinos en el Exilio liderado por Ongaro repartió profusamente una "Carta Abierta” que se dirigía a todas las delegaciones presentes en la OIT. En ella se presentaba la situación argentina haciendo énfasis en la violación de las obligaciones internacionales por parte de la Junta Militar, la identidad de los "desaparecidos", presos y muertos como "trabajadores" y pidiendo por la solidaridad internacional para condenar al gobierno dentro del organismo ese mismo año.

18 La no mención de Argentina en 1979 como un país comprometido con la violación de los derechos sindicales y humanos fue cuestionada y se evaluó el informe como "insatisfactorio", señalando por ejemplo que "algunos párrafos especiales fueron debilitados; especialmente el que se refiere a Argentina es incompleto y equívoco, puesto que no refleja ni los debates en la Comisión [de Libertad Sindical] ni la situación actual del país", u otra mención en la Conferencia donde se señala que "la aplicación del criterio 7, por ejemplo en el caso de Argentina había sido prevista porque la Comisión opinó que la legislación y la práctica existentes en ese país en la actualidad no corresponden al Convenio núm. 87 (...) en la Comisión quedó claro que en Argentina no hay libertad sindical, pero eso no aparece ahora en el informe" (ver esos y otros testimonios en Actas de la sexagésima quinta Conferencia Anual de la OIT, 1979). En una entrevista personal en 2015, Roberto Pablo Payró, quien fuera director del área de publicaciones y traducción de la OIT, mencionó que circunstancialmente existían estas manipulaciones a las “menciones especiales” producto de la presión de los gobiernos y algunas veces de la misma dirección del organismo.

$\underline{19}$ El año siguiente Daniel Funes de Rioja, quien era asesor de la Unión Industrial Argentina, publicó en Buenos Aires un artículo en defensa de la nueva ley que cuestionaba las impugnaciones hechas en el marco del Caso 842 sobre el tema. Ignoraba (por supuestas "razones disciplinares") los otros aspectos del Caso en cuestión, especialmente la violación de los derechos humanos y la detención y desaparición de personas. Ver Funes de Rioja (1980) .

20 Esa expectativa no impidió que en 1981 se abrieran contra Argentina dos nuevos casos: el Caso 1060 y el Caso 1067. El primero era producto de una denuncia de la Confederación Internacional de Organizaciones Sindicales Libres (CIOLS) por la injerencia gubernamental en las actividades sindicales, demostrada en la prohibición militar de realizar un plenario gremial el 12 de mayo de ese mismo año. El segundo caso trataba una denuncia conjunta de la CIOLS y la Confederación Mundial del Trabajo (CMT) por la detención de dirigentes obreros ante el anuncio de la jornada de protesta del 22 de junio de 1981 (OIT Boletín Oficial, Vol. LXV, 1982, Serie B núm. 1).

$\underline{21}$ Este sector sindical, luego conocido como CGT Azopardo, reafirmó entonces su "repudio contra la subversión” y señaló “una actitud diferente hacia la opinión de personas o sectores discrepantes por parte del Gobierno”. Aprovechó la oportunidad para pedir, como gesto, la libertad de los detenidos por razones políticas (aquellos que estaban presos a disposición del Poder Ejecutivo, es decir, en forma pública), en particular de la ex Presidente Martínez de Perón (Actas de la Sexagésima Séptima Reunión, 1981, OIT y La Nación 31/05/1981).

$\underline{22}$ Téngase en cuenta que la Comisión de Expertos en Aplicación de Convenios y Recomendaciones (CEACR) de la OIT también formuló observaciones sobre la situación Argentina en éste período.

$\underline{23}$ Que las actividades de las dirigencias sindicales hayan ido adquiriendo a lo largo de estos primeros tres años del PRN un espacio de actuación mayor y que las prórrogas de mandato permitieran cierta normalidad en la administración interna de los sindicatos en el marco de las restricciones políticas generales fue lo que permitió, sostenemos, que cuando un sector de esa misma dirigencia nacional llamó a actuar en forma unificada para rechazar la nueva ley de asociaciones profesionales a fines de 1979, combinando ese reclamo con el que producía el plan económico, una significativa porción de los dirigentes sindicales sencillamente no respondió al llamado. Una indagación con mayores detalles puede verse en Zorzoli (2016a) . 
$\underline{24}$ Según el reporte el enviado italiano se habría encontrado "En primer lugar, con un grupo de diez dirigentes procedentes de dos agrupaciones conocidas como la Comisión Nacional del Trabajo y la Comisión de los 20. Entre los dirigentes de la primera de estas comisiones figuraba el Sr. Baldassini, secretario general de la Federación de Obreros y Empleados de Correos y Telecomunicaciones (FOECYT), miembro trabajador adjunto del Consejo de Administración. Estaban presentes en esta reunión representantes de los sectores de los seguros, la industria molinera, la industria fideera, el vidrio, los electricistas marítimos, los trabajadores del Estado, luz y fuerza, los ferroviarios y la industria plástica. En segundo lugar, recibió a un grupo de 12 dirigentes procedentes en su mayoría de una agrupación conocida como la Comisión de los 25, a la que se había unido un dirigente procedente de la Comisión de los 20 y tres dirigentes de una confederación independiente. Estaban representados en este grupo los sectores de trabajadores del papel, gastronómicos, petroleros del Estado, gas del Estado, petroleros privados, empleados del tabaco, taxistas, industrias gráficas, así como la enseñanza. En tercer lugar, recibió a un grupo de cuatro personas procedentes de la Comisión Permanente Nacional del Sindicalismo Libre. Entre éstos estaba representado el gremio de los plomeros. También recibió a un representante de la Central Latinoamericana de Trabajadores (CLAT)”. Ver Boletín Oficial Vol. LXIV, Serie B, 1981, OIT.

$\underline{25}$ Se trataba de Julio Isabelino Guillán, dirigente de FOETRA y Jorge Marelli, Secretario General del SMATA de San Justo.

$\underline{26}$ Los testimonios a los que hacía referencia no provenían, como se desprende de ésta presentación documental, de la dirigencia sindical argentina, sino de la documentación reunida en Ginebra en el trámite del Caso 842.

\section{Archivos y fuentes consultadas:}

Archivo Organización Internacional del Trabajo (A-OIT), Ginebra, Suiza.

Diarios La Nación, Clarín y Crónica, Argentina.

\section{Bibliografía mencionada}

Alexander, R. (2003). A History of Organized Labor in Argentina. Westport, Conn.: Praeger.

Alexander, R. (2009). International Labor Organizations and Organized Labor in Latin America and the Caribbean: A History. USA, ABC-CLIO.

Angell, A. (2013). Las Dimensiones Internacionales del Golpe de Estado Chileno. Política. Revista de Ciencia Política Universidad de Chile, Santiago, 51(2), 57-78.

Bastias Saavedra, M. (2013). Sociedad civil en dictadura: relaciones transnacionales, organizaciones y socialización política en Chile (1973-1993). Santiago de Chile: Ediciones Alberto Hurtado.

Basualdo, V. (2010). The ILO and the Argentine Dictatorship (1976-1983). En Jasmien van Daele (Ed.), ILO Histories Essays on the International Labour Organization and Its Impact on the World during the Twentieth Century (pp. 401-13). Bern; New York: Peter Lang.

Basualdo, V. (2014). El movimiento sindical argentino y sus relaciones internacionales: una aproximación al impacto e influencia de la CIOLS/ORIT desde fines de los '40 hasta mediados de los '80 en la Argentina.. Mundos do Trabalho, volumen 5 nro. 10.

Belloni Ravest, H. (1969). El sindicalismo argentino en la Organización Internacional del Trabajo. Buenos Aires: s/d. 
Canelo, P. (2008). El proceso en su laberinto: la interna militar de Videla a Bignone. Buenos Aires: Prometeo.

Caruso, L. (2014). La política laboral argentina en la inmediata posguerra: una perspectiva internacional, 1907-1925. Relaciones. Estudios de Historia y Sociedad, 138, 11-43.

Caterina, L. M. (2000). Los empresarios frente a la legislación laboral en la década del veinte: la Asociación del Trabajo. Revista de historia del derecho, 28, 251-308.

Daele, J.van (2010). Writing ILO Histories: A state of the Art. En Rodriguez García, M., Goethem, G. van, y Linden, M. van der (Eds.), ILO histories: essays on the International Labour Organization and its impact on the world during the twentieth century, (pp.13-40). International and comparative social history, v. 12. Bern ; New York: Peter Lang.

Dawyd, D. (2014). Raimundo Ongaro: dirigente sindical. Trayectoria de un peronista combativo en contextos de hostilidad (Argentina, 1966-1983). Abordajes. Revista de Trabajo Social, 2(1), 21-53.

Funes de Rioja, D. (1980). La libertad sindical y el caso número 842. Derecho del Trabajo, 8, año XL.

García, Y.M. (2013). El trabajo militante del exilio chileno en Francia: Contextualización, descripción, micro-medios de comunicación y sus impactos. Revista Izquierdas (Chile), 17, 81-92.

Godio, J. (1980). Historia del movimiento obrero latinoamericano. Caracas; México: Nueva Sociedad; Editorial Nueva Imagen.

Gravel. E., Duplessis, I., Gernigon, B., International Labour Office, International Labour Standards Department, y Freedom of Association Branch (2001). El Comité de Libertad Sindical: impacto desde su creación. Ginebra: OIT.

Guest, I. (1990). Behind the Disappearances: Argentina's Dirty War against Human Rights and the United Nations. Philadelphia: University of Pennsylvania Press.

Livingstone, G. (2017). Foreign Policy, Corporations and Social Movements. Britain and the Dictatorships of Argentina and Chile, 1973-82. En ILAS Lunchtime Seminars. London.

Lloret, R. (2016). Represión, derechos humanos y política exterior. El rol de los diplomáticos argentinos en el Comité de Derechos Humanos de la ONU (1976-1983). Papeles de Trabajo 10(17), 126-46.

McPherson, A.L., y Wehrli, Y. (2015). Beyond Geopolitics: New Histories of Latin America at the League of Nations. Albuquerque, New Mexico: University of New Mexico Press.

Mignone, E.F. (1986). Iglesia y dictadura: el papel de la Iglesia a la luz de sus relaciones con el régimen militar. Buenos Aires: Ediciones del Pensamiento Nacional.

Novaro, M., y Palermo, V. (2003). La dictadura militar, 1976-1983: del golpe de estado a la restauración democrática. Buenos Aires: Paidós.

Organización Internacional del Trabajo y Comité de Libertad Sindical (2006). La libertad sindical: recopilación de decisiones y principios del Comité de Libertad Sindical del Consejo de Administración de la OIT. Ginebra: Oficina Internacional del Trabajo.

Panettieri, J. (ed.). (2000). Argentina: Trabajadores entre dos guerras. Buenos Aires: Editorial Universitaria de Buenos Aires.

Rodgers, G., Lee, E., Swepston, L., y van Daele, J. (2009). La Organización Internacional del Trabajo y la lucha por la justicia social, 1919-2009. Ginebra: OIT. 
Sangrilli, C. (2011) La normalización de la CGT. Un análisis del Consejo Directivo elegido en noviembre de 1986. En Fabris, M. y Tortorella, R., Democracia en reconstrucción: mosaico histórico de los años ochenta. Mar del Plata, Argentina: EUDEM.

Stagnaro, A. (en prensa). Profecía autocumplida. La delegación argentina en Washington (1919): entre el prestigio internacional y la acción local. En Caruso, L. y Stagnaro A (comp.), Regular y Legislar el mundo del trabajo Latinoamericano. Aportes para una historia regional de la OIT. La Plata: Publicaciones de la FaHCE.

Suriano, J. (2012). El Departamento Nacional de Trabajo y la política laboral durante el primer gobierno de Hipólito Yrigoyen. En Plotkin, M.B. y Zimmermann, E. (comp.), Los saberes del Estado (pp. 35-62). Buenos Aires: Edhasa.

Suriano, J., y Lobato, M. Z. (2014). La sociedad del trabajo: las instituciones laborales en la Argentina, 19001955. Buenos Aires: Edhasa.

Verhaert, P. (2016). The Articulation of Belgian Solidarity for Argentina and Chile: a Comparative Analysis. En Rethinking the «proceso». The argentinian dictatorship in perspective (1976-2016). London: UCL.

Yannuzzi, M. A. (1996). Política y dictadura: los partidos políticos y el «proceso de reorganización nacional» 1976-1982. Rosario: Editorial Fundación Ross.

Zanatta, L. y Aguas, M. (2005). Auge y declinación de la tercera posición. Bolivia, Perón y la guerra fría, 1943-1954. Desarrollo Económico, 45(177), 25.

Zorzoli, L. (en prensa). Las intervenciones a organizaciones sindicales durante la última dictadura militar argentina: un estudio cuantitativo. Desarrollo Económico.

Zorzoli, L. (2016a). Los sindicatos y el gobierno militar. Un estudio de sus relaciones a partir de la participación en la Organización Internacional del Trabajo (1976-1983). Tesis doctoral inédita). Universidad de Buenos Aires, Facultad de Ciencias Sociales, Buenos Aires, Argentina.

Zorzoli, L. (2016b) “Operativo Ginebra”. La dirigencia sindical ante la instalación internacional de la dictadura militar (1976). Revista Archivos de Historia del Movimiento Obrero y la Izquierda IV(8), 12-32. 